\title{
Mangrove canopy height globally related to precipitation, temperature and cyclone frequency
}

\author{
Marc Simard ${ }^{1 \star}{ }^{\star}$, Lola Fatoyinbo ${ }^{2 *}$, Charlotte Smetanka ${ }^{1,3}$, Victor H. Rivera-Monroy ${ }^{4}$, \\ Edward Castañeda-Moya ${ }^{4,5}$, Nathan Thomas ${ }^{2,6}$ and Tom Van der Stocken (1) 1
}

\begin{abstract}
Mangrove wetlands are among the most productive and carbon-dense ecosystems in the world. Their structural attributes vary considerably across spatial scales, yielding large uncertainties in regional and global estimates of carbon stocks. Here, we present a global analysis of mangrove canopy height gradients and aboveground carbon stocks based on remotely sensed measurements and field data. Our study highlights that precipitation, temperature and cyclone frequency explain $74 \%$ of the global trends in maximum canopy height, with other geophysical factors influencing the observed variability at local and regional scales. We find the tallest mangrove forests in Gabon, equatorial Africa, where stands attain $62.8 \mathrm{~m}$. The total global mangrove carbon stock (above- and belowground biomass, and soil) is estimated at $5.03 \mathrm{Pg}$, with a quarter of this value stored in Indonesia. Our analysis implies sensitivity of mangrove structure to climate change, and offers a baseline to monitor national and regional trends in mangrove carbon stocks.
\end{abstract}

M angroves are forested wetlands that represent a functional link between the terrestrial and oceanic carbon cycles ${ }^{1}$, storing up to four times as much carbon per unit area in comparison to terrestrial forest ecosystems ${ }^{2}$. Mangroves contribute an estimated $10-15 \%$ of the global carbon storage in the coastal ocean, with $\sim 50 \%$ of mangrove litterfall production being transported to adjacent coastal zones and accounting for $10-11 \%$ of the global export of particulate terrestrial carbon to the ocean ${ }^{3,4}$. Furthermore, mangrove forests provide a wealth of ecosystem services to coastal communities, including habitat for fisheries, firewood and timber, all valuable resources in local markets 5 . Despite this, mangroves are impacted by anthropogenically driven disturbances such as deforestation, conversion to aquaculture and urban development ${ }^{6-8}$, and coastline transgression due to relative sea level rise ${ }^{9-11}$. Recent estimates of global mangrove loss rates range between $0.16 \%$ and $0.39 \%$ annually, and may be up to $8.08 \%$ in Southeast Asia ${ }^{12}$. As a consequence, large amounts of previously stored carbon may be released into the atmosphere, contributing substantially to net global carbon emissions ${ }^{13-15}$.

Global mangrove carbon stocks ${ }^{2}$ and aboveground biomass (AGB $)^{16,17}$ have been estimated previously, providing AGB values derived from climate-based ${ }^{16}$ or latitudinal relationships ${ }^{17}$. The spatially explicit distribution in forest structural attributes such as mangrove canopy height is rarely considered in these estimates. Mangrove canopy height is highly correlated with carbon turnover via leaf or litterfall production ${ }^{18}$ and is therefore an important variable in quantifying contemporary global aboveground productivity and carbon sequestration rates. Productivity and forest structure are controlled by local environmental gradients (for example, nutrient availability and salinity) and hydrology ${ }^{19,20}$, along with regional climate and geomorphology ${ }^{17,19-22}$, resulting in a range of mangrove ecotypes, from scrub $(<3 \mathrm{~m})$ to tall $(>15 \mathrm{~m})$ forest stand $\mathrm{s}^{23-25}$. Here, we produce global maps of mangrove canopy height and AGB derived from space-borne remote sensing data and in situ measurements, to perform a global analysis of the spatial patterns and variability in mangrove forest structure.

\section{Global distribution of mangrove canopy height}

We used the global mangrove extent map $^{26}$, the Shuttle Radar Topography Mission (SRTM) $30 \mathrm{~m}$ resolution global digital elevation model (DEM), and Geoscience Laser Altimeter System (GLAS) global Lidar altimetry products to produce two baseline canopy height maps for the year 2000: a map of maximum canopy height (that is, height of the tallest tree; Fig. 1) and a map of basal area weighted height (that is, individual tree heights weighted in proportion to their basal area). The latter map was used to generate the aboveground mangrove biomass map (see Methods). Our analysis of mangrove canopy height distribution is based on the maximum canopy height map. Both maps were validated using in situ field measurements of tree height from 331 plots (Supplementary Table 1), resulting in overall root-mean-square errors of $3.6 \mathrm{~m}$ and $6.3 \mathrm{~m}$, respectively (Supplementary Fig. 1). The maximum canopy height map shows that half of the world's maximum mangrove canopy height is shorter than $13.2 \mathrm{~m}$ (Fig. 2). The maximum canopy height exceeds $62 \pm 6.8 \mathrm{~m}$ (Fig. 2), rivaling maximum tree heights found in upland tropical forests ${ }^{27}$. Equatorial regions of the West African and South American coasts stand out as hotspots with the tallest mangroves (Table 1a and Supplementary Tables 2-6). The top five countries (Table 1a) with the tallest mangroves are Gabon $(62.8 \mathrm{~m}$, Fig. 3), Equatorial Guinea (57.7 m), Colombia (54.3 m), Venezuela $(52.6 \mathrm{~m})$ and Panama $(50.9 \mathrm{~m})$. These productive forests are significantly taller than previously reported values ${ }^{16,18,28}$ and are located in estuarine environments of the world's most remote, cloudiest, wettest (precipitation $>500 \mathrm{~cm} \mathrm{yr}^{-1}$ ) and hottest (mean air temperature $25.6^{\circ} \mathrm{C}$, ref. ${ }^{29}$ ) regions. In addition, these wetlands grow in riverdominated coastal settings with low human population densities,

${ }^{1}$ Radar Science and Engineering Section, Jet Propulsion Laboratory, California Institute of Technology, Pasadena, CA, USA. ${ }^{2}$ Biospheric Sciences Laboratory, NASA Goddard Space Flight Center, Greenbelt, MD, USA. ${ }^{3}$ Department of Applied Geomatics, Université de Sherbrooke, Sherbrooke, Québec, Canada. ${ }^{4}$ Department of Oceanography and Coastal Sciences, College of the Coast and Environment, Lousiana State University, Baton Rouge, LA, USA. ${ }^{5}$ Present address: Southeast Environmental Research Center, Florida International University, Miami, FL, USA. ${ }^{6}$ Earth System Science Interdisciplinary Center, University of Maryland, College Park, MD, USA. *e-mail: marc.simard@jpl.nasa.gov; lola.fatoyinbo@nasa.gov 
a

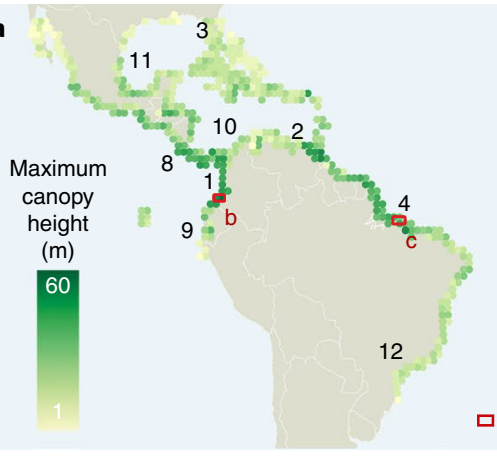

b
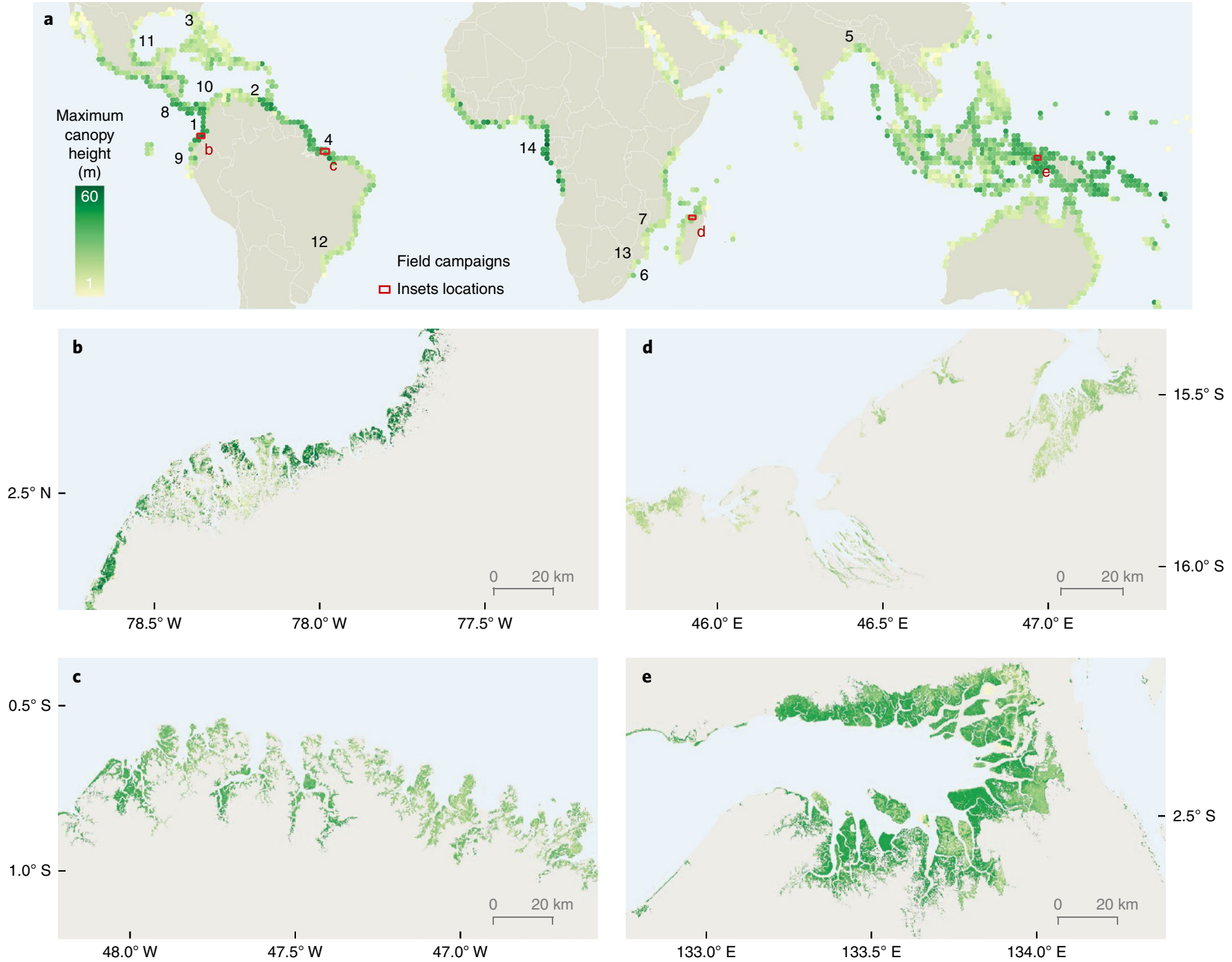

Fig. 1 | Global map of mangrove maximum canopy height and location of sampling sites (numbers) where in situ data were collected. a, Green colours show tallest maximum mangrove canopy height found within $1^{\circ}$ cells. The map also shows the locations of the field sites and the locations of the high-resolution insets in b-e. b, Coastal Nariño and Cauca (Colombia). c, Coastal Pará (Brazil). d, Bombetoka Bay (Madagascar). e, Bintuni Bay (West Papua, Indonesia).

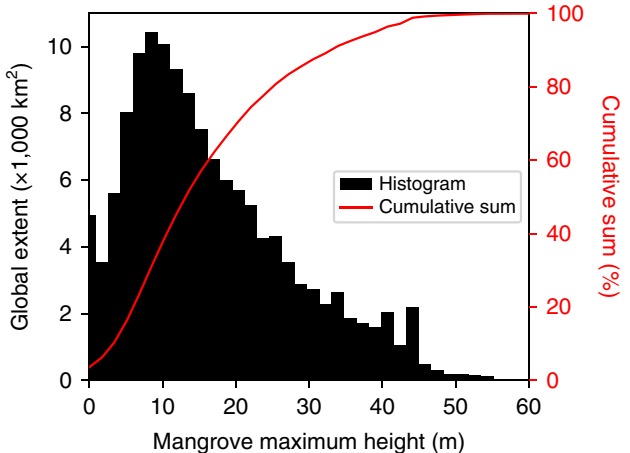

Fig. 2 | Global distribution of maximum mangrove canopy height extent. Areal extent of forests within each height class at $1.7 \mathrm{~m}$ intervals (black) and cumulative sum of the percentages (red).

potentially high nutrient availability, reduced soil salinity values and significant protection from cyclone-induced high-energy winds and waves ${ }^{17,30}$.
We analysed global trends in mangrove canopy height with latitude, cyclone landfall frequency, precipitation, temperature, sea surface salinity (SSS) and tidal range. Globally, the distribution of maximum mangrove canopy height follows a Gaussian latitudinal trend $\left(R^{2}=0.91\right)$, peaking at $1.13^{\circ} \mathrm{N}$ (Fig. $4 \mathrm{a}$ ), similar to trends of precipitation and temperature. The global distribution of canopy height suggests that cyclone landfall frequency may limit the growth of mangrove forests (Fig. 4a). Cyclone disturbance has been shown to be important at more regional scales ${ }^{31}$. However, the impact may be confounded by other environmental factors (Fig. 4b). Our results indicate that coastline-specific trends in maximum canopy height reflect the important role of precipitation (Fig. 4b) in controlling mangrove structure and distribution, as shown recently by Osland and colleagues $^{32}$. For example, the trends reflect similar differences between the east and west coasts of the Americas and Africa. While large-scale SSS appears to align with mangrove canopy height (Fig. 4b), the explanatory role of this factor remains unclear as it varies strongly over short distances in estuarine environments, and is regulated by precipitation, evapotranspiration, riverine input and ocean circulation ${ }^{33}$. We did not find a significant relationship of canopy height variability with local tidal range (see Methods and 
Table 1 | Distribution of mangrove canopy height and total AGB

(a) Ten countries with the tallest maximum mangrove canopy height

\begin{tabular}{|c|c|c|c|c|c|c|c|c|}
\hline & Country & $\begin{array}{l}\text { Max } \\
\text { height (m) }\end{array}$ & $\begin{array}{l}\text { Mean } \\
\text { height (m) }\end{array}$ & $\begin{array}{l}\text { Max AGB } \\
\left(\mathrm{Mgha}^{-1}\right)\end{array}$ & $\begin{array}{l}\text { Mean AGB } \\
\left(\mathrm{Mgha}^{-1}\right)\end{array}$ & $\begin{array}{l}\text { Total } \\
\text { AGB (Mg) }\end{array}$ & $\begin{array}{l}\text { Total } \\
\text { carbon (Mg) }\end{array}$ & $\begin{array}{l}\text { Mangrove } \\
\text { area (ha) }\end{array}$ \\
\hline 1 & Gabon & 62.8 & 23.5 & 910.5 & 244.0 & $33,578,276$ & $61,504,323$ & 137,597 \\
\hline 2 & Equatorial Guinea & 57.7 & 21.6 & 800.0 & 208.6 & $2,630,892$ & $5,337,399$ & 12,613 \\
\hline 3 & Colombia & 54.3 & 24.0 & 413.3 & 129.5 & $26,648,548$ & $75,973,344$ & 205,179 \\
\hline 4 & Venezuela & 52.6 & 30.7 & 392.8 & 184.0 & $45,505,364$ & $100,551,457$ & 247,252 \\
\hline 5 & Panama & 50.9 & 27.7 & 372.6 & 155.6 & $23,676,218$ & $58,979,743$ & 152,189 \\
\hline 6 & French Guyana & 49.2 & 23.2 & 352.9 & 129.2 & $10,290,431$ & $29,453,310$ & 79,640 \\
\hline 7 & Cameroon & 47.5 & 22.6 & 594.5 & 208.7 & $41,603,704$ & $84,360,030$ & 199,303 \\
\hline 8 & Angola & 45.8 & 16.6 & 562.3 & 139.7 & $3,738,534$ & $10,090,736$ & 26,779 \\
\hline 9 & Costa Rica & 45.8 & 23.4 & 314.7 & 116.4 & $4,512,007$ & $13,998,836$ & 38,752 \\
\hline 10 & Papua New Guinea & 45.8 & 27.7 & 432.5 & 242.4 & $113,948,576$ & $209,577,515$ & 469,983 \\
\hline
\end{tabular}

(b) The largest total AGB pools

\begin{tabular}{|c|c|c|c|c|c|c|c|c|}
\hline & Country & $\begin{array}{l}\text { Max } \\
\text { height (m) }\end{array}$ & $\begin{array}{l}\text { Mean } \\
\text { height }(\mathrm{m})\end{array}$ & $\begin{array}{l}\text { Max AGB } \\
\left(\mathrm{Mgha}^{-1}\right)\end{array}$ & $\begin{array}{l}\text { Mean AGB } \\
\left(\mathrm{Mgha}^{-1}\right)\end{array}$ & $\begin{array}{l}\text { Total } \\
\text { AGB (Mg) }\end{array}$ & $\begin{array}{l}\text { Total } \\
\text { carbon (Mg) }\end{array}$ & $\begin{array}{l}\text { Percent of global } \\
\text { AGB }(\%)\end{array}$ \\
\hline 1 & Indonesia & 44.1 & 24.3 & 409.5 & 215.3 & $574,318,208$ & $1,140,797,712$ & 32.7 \\
\hline 2 & Papua New Guinea & 45.8 & 27.7 & 432.5 & 242.4 & $113,948,576$ & $209,577,515$ & 6.5 \\
\hline 3 & Australia & 25.5 & 11.9 & 212.6 & 119.4 & $112,797,816$ & $342,085,251$ & 6.4 \\
\hline 4 & Brazil & 40.7 & 19.9 & 260.5 & 92.5 & $97,833,808$ & $363,245,344$ & 5.6 \\
\hline 5 & Malaysia & 33.9 & 19.9 & 290.6 & 172.9 & $95,561,040$ & $220,641,786$ & 5.4 \\
\hline 6 & Bangladesh & 25.5 & 15.4 & 421.2 & 171.7 & $73,916,552$ & $171,532,878$ & 4.2 \\
\hline 7 & Nigeria & 33.9 & 13.4 & 355.3 & 96.5 & $66,791,716$ & $240,715,439$ & 3.8 \\
\hline 8 & Myanmar & 30.5 & 13.7 & 257.3 & 130.7 & $61,974,552$ & $175,266,415$ & 3.5 \\
\hline 9 & Venezuela & 52.6 & 30.7 & 392.8 & 184.0 & $45,505,364$ & $100,551,457$ & 2.6 \\
\hline \multirow[t]{2}{*}{10} & Cameroon & 47.5 & 22.6 & 594.5 & 208.7 & $41,603,704$ & $84,360,030$ & 2.4 \\
\hline & Total top $10 \mathrm{AGB}$ & & & & & $1,284,251,336$ & $3,048,773,825$ & 73.2 \\
\hline
\end{tabular}

Supplementary Fig. 2). A multivariate regression analysis shows that annual precipitation, mean temperature and tropical cyclone landfall frequency explain $74 \%$ of latitudinal trends in maximum mangrove canopy height (see Methods and Supplementary Table 7).

The spatial variability in canopy height also reflects the role of local-scale geophysical factors driving environmental gradients within distinct ecogeomorphic settings (for example, nutrient availability and soil pore water salinity $)^{20,34}$. For instance, where we located the tallest mangrove canopy height in the upper Gabon estuary (Africa, Fig. 3), we also detected low stature mangrove wetlands near the mouth of the same estuary (see also ref. ${ }^{35}$ ). The relative influence of regional and local factors within a given latitude hosting a diversity of ecogeomorphic settings ${ }^{17}$ determines not only the species-specific mangrove spatial distribution in a given coastal region, but also the spatial distribution of above- and belowground biomass allocation patterns, regardless of latitude ${ }^{36}$. However, quantifying the relative contributions of these factors to the global variability observed in our canopy height map is beyond the scope of this study, particularly because they currently cannot be resolved by remote sensing measurements. Instead, our maps can help define research agendas and field campaigns to quantify the relative contribution of local drivers such as hydroperiod, a critical factor controlling nutrient availability and soil salinity in mangrove wetlands ${ }^{24}$.

\section{Global trends of mangrove biomass and carbon stocks}

Much attention is directed at mangrove forests because of their significant allocation of carbon belowground ${ }^{2,3,36-39}$. However, carbon sequestration rates are estimated by using wood production and litterfall rates, which are positively correlated with tree height and $\mathrm{AGB}^{9,18}$. We developed and validated regional and global AGB models (Supplementary Table 8) from 331 field plots distributed across three continents (Fig. 1), spanning $51^{\circ}$ in latitude and $168^{\circ}$ in longitude (see Methods).

Our maps indicate that mangroves can store substantial aboveground carbon stocks (maximum AGB of $910.5 \pm 84.2 \mathrm{Mgha}^{-1}$, Table 1a), and show considerable spatial variability. Similar to canopy height, the global distribution of AGB maxima in mangrove forests follows a Gaussian latitudinal trend with a peak near $0.47^{\circ} \mathrm{S}$ (Supplementary Fig. 3). The top five countries in terms of total AGB are (Table 1b): Indonesia (574.3 Tg, 2.7 Mha), Papua New Guinea (114.0 Tg, 0.5 Mha), Australia (112.8 Tg, 0.9 Mha), Brazil (97.8 Tg, 1.1 Mha) and Malaysia (95.6 Tg, 0.6 Mha). These countries are characterized by vast expanses of mangrove forests and a high proportion of tall stands. The top ten list (Table 1b) differs from previously reported rankings that include Indonesia and Papua New Guinea, but not Bangladesh, Myanmar, Venezuela and Cameroon ${ }^{16}$. Furthermore, our field data set underscores major regional differences in allometric relationships between canopy height and AGB (Supplementary Fig. 4 and Supplementary Table 8). For example, our allometric model for East African coastal regions derived from in situ data shows that, for the same forest canopy height, AGB in East Africa is significantly higher than in the Americas. This difference in values highlights the relative importance of tree density ${ }^{40}$ when calculating AGB in sites within the same latitude, and the need to develop regional allometry covering a wide range of environmental settings. 


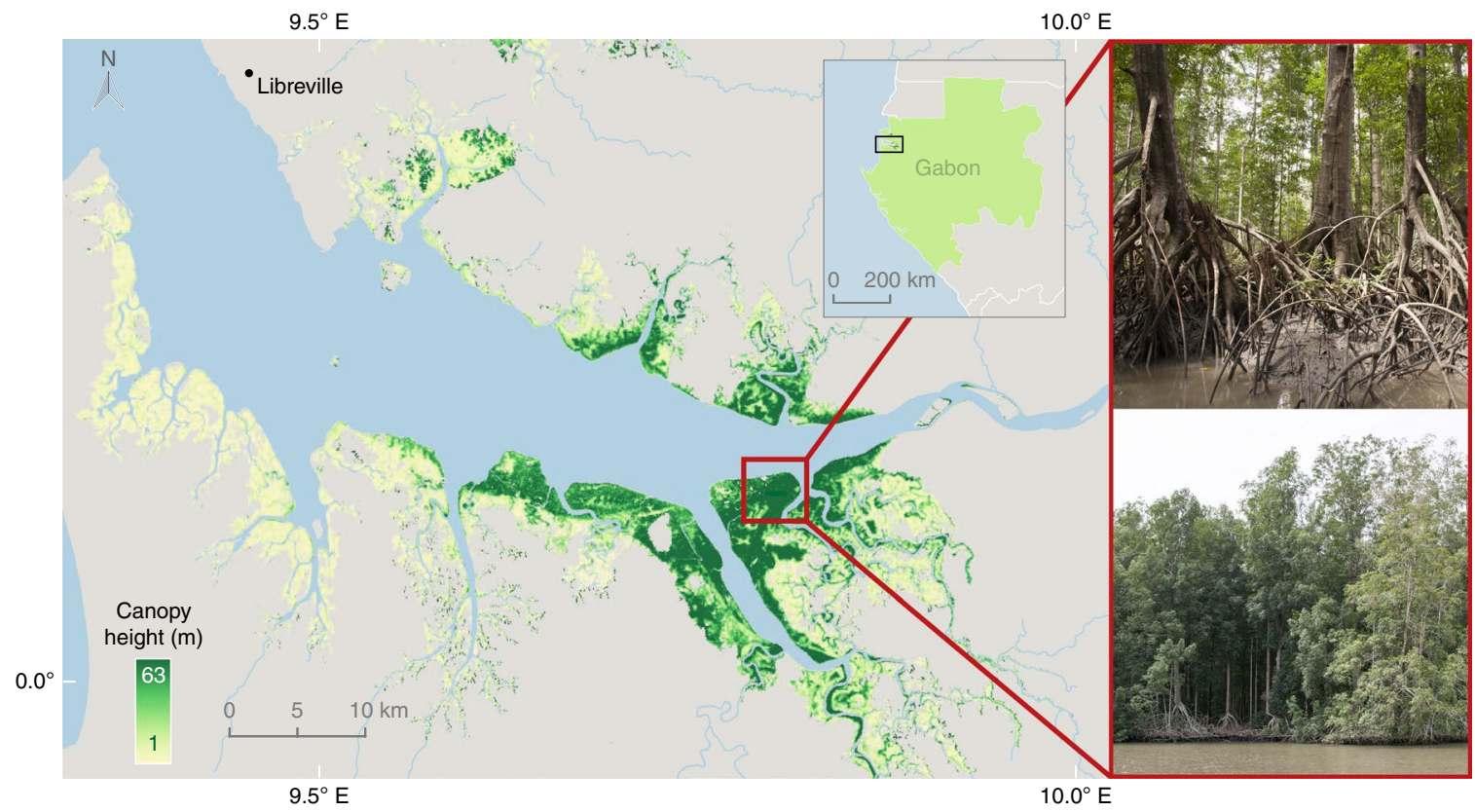

Fig. 3 | Distribution of mangrove canopy height in the Gabon Estuary, on the Atlantic coast of Equatorial Africa. This map highlights the tallest mangrove forests globally with forest stands that were measured at $63 \mathrm{~m}$ on our map. The photo insets show locations where individual trees were measured in situ up to $65 \mathrm{~m}$ tall.

When adding our global aboveground carbon stock value to recently published values for average organic soil carbon stock $\left(283 \mathrm{MgCha}^{-1}\right.$; ref. ${ }^{41}$ ) and root biomass (from allometric models, see ref. ${ }^{42}$ ), we obtain a total global carbon stock estimate of $5.03 \mathrm{Pg}$, of which nearly a quarter $(22.7 \%)$ is stored in Indonesia (see Supplementary Tables 2-6 for the per country and per continent overview). Our estimate is in line with recently published total carbon stock estimates (Supplementary Table 9), in part due to the significant contribution of belowground carbon to the total global carbon estimate.

While our estimates of total global AGB (1.75 Pg) and mean AGB density $\left(129.1 \pm 87.2 \mathrm{Mgha}^{-1}\right)$ are significantly lower than previously reported by Hutchison and colleagues ${ }^{16}(2.83 \mathrm{Pg}$ and $184.8 \mathrm{Mg} \mathrm{ha}^{-1}$, respectively), our total is close to the mean $(1.88 \mathrm{Tg})$ of a range of published values (Supplementary Table 9). The difference in estimates is primarily due to methodological approaches such as the use of different mangrove extent maps. Additionally, a few previous AGB estimates, such as the one of Hutchison and colleagues ${ }^{16}$, represent the potential AGB obtained by modelling biomass based on latitude ${ }^{43,44}$ and bioclimatic variables ${ }^{16}$. In contrast, our estimate is based on direct measurements of canopy height from spaceborne radar and lidar instruments, coupled with extensive in situ forest structure and composition measurements. As such, the differences between our estimates and those reported in previous studies reflect local-scale variability within mangrove forests and areas where mangroves are stressed or impacted by environmental and geophysical factors, and anthropogenic activity. For example, the differences in mean AGB between studies (shown as 'satellite-based' from this study versus 'environmental model' from ref. $\left.{ }^{16}\right)$ in West Africa are as follows: Benin $\left(10.0 \mathrm{Mgha}^{-1}\right.$ versus 160.6 $\mathrm{Mgha}^{-1}$ ), Ghana (59.8 $\mathrm{Mgha}^{-1}$ versus $\left.166.9 \mathrm{Mgha}^{-1}\right)$, Nigeria (96.5 $\mathrm{Mgha}^{-1}$ versus $195.1 \mathrm{Mgha}^{-1}$ ), Sierra Leone $\left(74.7 \mathrm{Mgha}^{-1}\right.$ versus $180.2 \mathrm{Mgha}^{-1}$ ) and The Gambia (42.0 $\mathrm{Mgha}^{-1}$ versus 144.9 $\mathrm{Mgha}^{-1}$ ), suggesting that model-based estimates may have overestimated AGB by $100 \mathrm{Mgha}^{-1}$ or more. Mangrove wetlands in these regions are heavily impacted by anthropogenic pressures such as wood harvesting, bio-fuel plantations, development projects and industrial pollution ${ }^{45}$, and may explain discrepancies. Industrial pollution, for example, is a common cause of mangrove degradation in the Niger Delta region (Nigeria) ${ }^{46}$. Similarly, our total carbon estimate for Indonesia $(1,141 \mathrm{TgC})$ is less than half of that reported by Murdiyarso and colleagues ${ }^{7}(3,140 \mathrm{TgC})$. This discrepancy is due to differences in the soil depth ( $1 \mathrm{~m}$ in this study; $2-3 \mathrm{~m}$ in ref. ${ }^{7}$ ) that is being considered for estimating the soil carbon component and our use of a smaller total mangrove area (2.7 Mha versus 4.2 Mha). These findings also suggest that regions with deep carbon-rich soils can potentially yield higher values than those reported in this study. While we report on the top $1 \mathrm{~m}$ of soil as a first-order conservative estimate, we foresee the continued development of more spatially explicit maps of soil carbon in blue carbon ecosystems ${ }^{36,37,47}$ that can be coupled with our AGB and carbon data sets.

\section{Baseline for monitoring regional and global carbon trends}

In this study we have shown that mangroves can store substantial aboveground carbon stocks and that continental to global patterns of mangrove canopy height and AGB follow precipitation, temperature and cyclone landfall frequency trends. Moreover, our spatially explicit maps indicate that local-scale geophysical and environmental conditions also regulate forest structure, and therefore carbon stocks and sequestration rates. Our mangrove canopy height map revealed a vast range of canopy heights, including maximum realized values $(>62 \mathrm{~m})$ that surpass maximum heights of other forest types worldwide $^{27}$, and the discovery of the tallest stands of mangrove forests in the world, on the Atlantic coast of equatorial Africa and the Pacific coast of South America. Our AGB map can serve as a baseline input for estimating the contribution of mangroves to carbon sequestration by wetlands in general and the potential contribution of $\mathrm{CO}_{2}$ emissions resulting from mangrove degradation and loss $\mathrm{s}^{15,39,43}$.

\section{Online content}

Any methods, additional references, Nature Research reporting summaries, source data, statements of data availability and associated accession codes are available at https://doi.org/10.1038/ s41561-018-0279-1. 


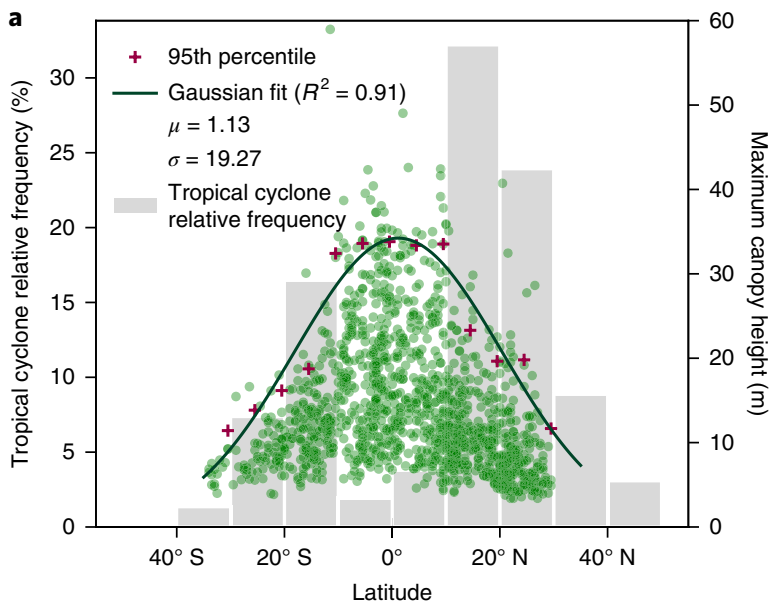

b
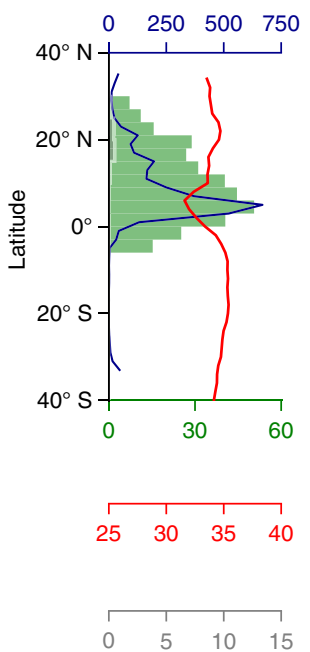

Americas

Pacific Ocean
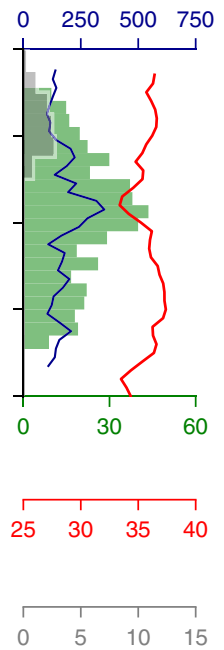

Americas Atlantic Ocean
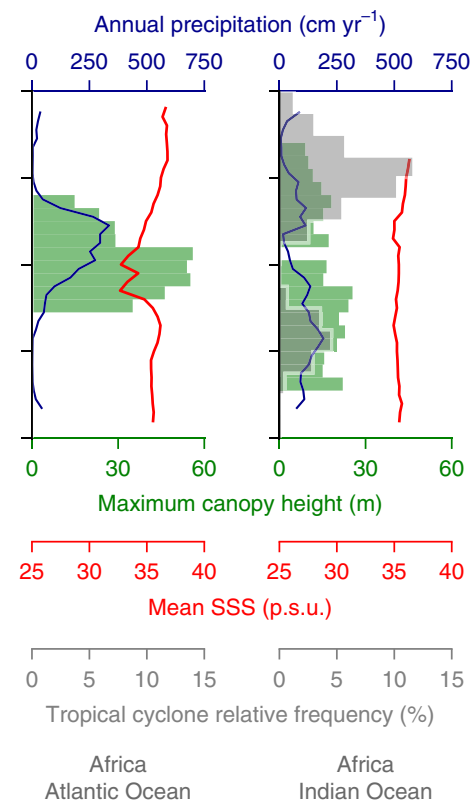
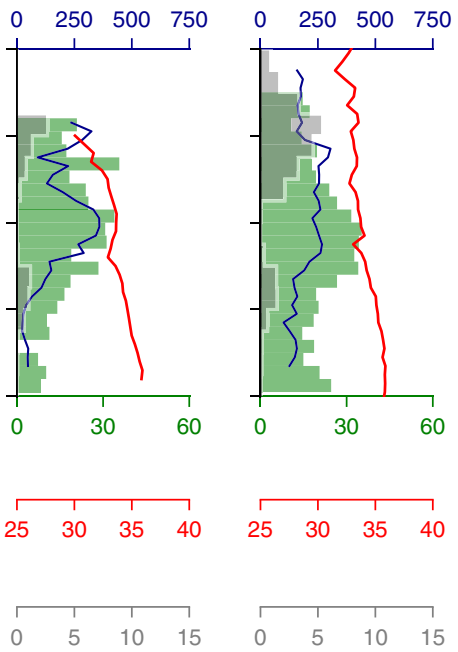

Asia

Indian Ocean

\section{Asia}

Pacific Ocean

Fig. 4 | Latitudinal variation of maximum canopy height $(\mathrm{m})$ and global environmental variables. a, Relationship (black line) between latitude and maximum canopy height (green circles) calculated on the 95th percentile of maximum canopy height (red plus symbols) (right $y$ axis) at every $5^{\circ}$ of latitude between about $30^{\circ} \mathrm{S}$ and $30^{\circ} \mathrm{N}$ (that is, where most mangroves occur). Tropical cyclone frequency (left $y$ axis) is shown in grey. b, Latitudinal trends in maximum canopy height (green bars), precipitation (blue line), SSS (red line) and cyclone relative frequency distribution (grey bins) along the major continental coastlines. p.s.u., practical salinity unit (grams of salt per 1,000 grams of water).

Received: 3 April 2018; Accepted: 20 November 2018;

Published online: 20 December 2018

\section{References}

1. McLeod, E. et al. A blueprint for blue carbon: toward an improved understanding of the role of vegetated coastal habitats in sequestering $\mathrm{CO}_{2}$. Front. Ecol. Environ. 9, 552-560 (2011).

2. Donato, D. C. et al. Mangroves among the most carbon-rich forests in the tropics. Nat. Geosci. 4, 293-297 (2011).

3. Alongi, D. M. Carbon cycling and storage in mangrove forests. Annu. Rev. Mar. Sci 6, 195-219 (2014).

4. Bouillon, S. et al. Mangrove production and carbon sinks: a revision of global budget estimates. Global. Biogeochem. Cycles 22, GB2013 (2008).

5. Barbier, E. B. et al. The value of estuarine and coastal ecosystem services. Ecol. Monogr. 81, 169-193 (2011).

6. Polidoro, B. A. et al. The loss of species: mangrove extinction risk and geographic areas of global concern. PLoS ONE 5, e10095 (2010).

7. Murdiyarso, D. et al. The potential of Indonesian mangrove forests for global climate change mitigation. Nat. Clim. Change 5, 8-11 (2015).

8. Richards, D. R. \& Friess, D. A. Rates and drivers of mangrove deforestation in Southeast Asia, 2000-2012. Proc. Natl Acad. Sci. USA 113, 344-349 (2016).
9. Krauss, K. W. et al. How mangrove forests adjust to rising sea level. New Phytol. 202, 19-34 (2014).

10. Lovelock, C. et al. The vulnerability of Indo-Pacific mangrove forests to sea-level rise. Nature 526, 559-563 (2015).

11. Sasmito, S. D., Murdiyarso, D., Friess, D. \& Kurniato, S. Can mangroves keep pace with contemporary sea level rise? A global data review. Wetlands Ecol. Manage. 24, 263-278 (2016).

12. Hamilton, S. E. \& Casey, D. Creation of a high spatio-temporal resolution global database of continuous mangrove forest cover for the 21 st century (CGMFC-21). Glob. Ecol. Biogeogr. 25, 729-738 (2016).

13. Lovelock, C. E., Reuss, R. W. \& Feller, I. C. $\mathrm{CO}_{2}$ efflux from cleared mangrove peat. PLoS ONE 6, e21279 (2011).

14. Kauffman, J. B., Heider, C., Norfolk, J. \& Payton, F. Carbon stocks of intact mangroves and carbon emissions arising from their conversion in the Dominican Republic. Ecol. Appl. 24, 518-527 (2014).

15. Hamilton, S. E. \& Friess, D. A. Global carbon stocks and potential emissions due to mangrove deforestation from 2000 to 2012. Nat. Clim. Change $\mathbf{8}$, 240-244 (2018).

16. Hutchison, J., Manica, A., Swetnam, R., Balmford, A. \& Spalding, M. Predicting global patterns in mangrove forest biomass. Conserv. Lett. 7, 233-240 (2014).

17. Rovai, A. S. et al. Scaling mangrove aboveground biomass from site-level to continental-scale. Glob. Ecol. Biogeogr. 25, 286-298 (2016). 
18. Saenger, P. \& Snedaker, S. C. Pantropical trends in mangrove above-ground biomass and annual litterfall. Oecologia 96, 293-299 (1993).

19. Twilley, R. R. \& Rivera-Monroy, V. H. in Coastal Wetlands: An Integrated Ecosystem Approach (eds Perillo, G. M. E. et al.) Ch. 23 (Elsevier, Amsterdam, 2009).

20. Thom, B. G. in Mangrove Ecosystems in Australia (ed. Clough, B. F.) 3-17 (Australian National Univ. Press, Canberra, 1982).

21. Danielson, T. M. et al. Assessment of Everglades mangrove forest resilience: implications for above-ground net primary productivity and carbon dynamics. Forest Ecol. Manage. 404, 115-125 (2017).

22. Twilley, R. R. et al. in Mangrove Ecosystems: A Global Biogeographic Perspective (eds Rovera-Monroy, V. H. et al.) Ch. 5 (Springer, Basel, 2017).

23. Simard, M., Rivera-Monroy, V. H., Mancera-Pineda, J. E., Castañeda-Moya, E. \& Twilley, R. R. A systematic method for 3D mapping of mangrove forests based on Shuttle Radar Topography Mission elevation data, ICEsat/GLAS waveforms and field data: application to Ciénaga Grande de Santa Marta, Colombia. Remote Sens. Environ. 112, 2131-2144 (2008).

24. Castañeda-Moya, E., Twilley, R. R. \& Rivera-Monroy, V. H. Allocation of biomass and net primary productivity of mangrove forests along environmental gradients in the Florida coastal Everglades, USA. Forest Ecol. Manage. 307, 226-241 (2013).

25. Balke, T. \& Friess, D. A. Geomorphic knowledge for mangrove restoration: a pan-tropical categorization. Earth Surf. Process. Landforms 41, 231-239 (2016).

26. Giri, C. et al. Status and distribution of mangrove forests of the world using earth observation satellite data. Glob. Ecol. Biogeogr. 20, 154-159 (2011)

27. Simard, M., Pinto, N., Fisher, J. B. \& Baccini, A. Mapping forest canopy height globally with spaceborne lidar. J. Geophys. Res. Biogeosci. 116, G04021 (2011).

28. Pan, Y., Birdsey, R. A., Phillips, O. L. \& Jackson, R. B. The structure, distribution, and biomass of the world's forests. Annu. Rev. Ecol. Evol. Syst. 44, 593-622 (2013).

29. Hijmans, R. J., Cameron, S. E., Parra, J. L., Jones, P. G. \& Jarvis, A. Very high resolution interpolated climate surfaces for global land areas. Int. J. Climatol. 25, 1965-1978 (2005).

30. Ward, R. D., Friess, D. A., Day, R. H. \& MacKenzie, R. A. Impacts of climate change on mangrove ecosystems: a region by region overview. Ecosyst. Health Sustain. 2, e01211 (2016).

31. Farfán, L. M., D’Sa, E. J., Liu, K.-b \& Rivera-Monroy, V. H. Tropical cyclone impacts on coastal regions: the case of the Yucatán and the Baja California Peninsulas, Mexico. Estuar. Coasts 37, 1388-1402 (2014).

32. Osland, M. J. et al. Climatic controls on the global distribution, abundance, and species richness of mangrove forests. Ecol. Monogr. 87, 341-359 (2017).

33. Terray, L. et al. Near-surface salinity as nature's rain gauge to detect human influence on the tropical water cycle. J. Clim. 25, 958-977 (2012).

34. Twilley, R. R. in Maximum Power: the Ideas and Applications of H.T. Odum (ed. Hall, C. A. S.) 43-62 (Univ. Press Colorado, Niwot, 1995).

35. Kauffman, J. B. \& Bhomia, R. K. Ecosystem carbon stocks of mangroves across broad environmental gradients in West-Central Africa: global and regional comparisons. PLoS ONE 12, e0187749 (2017).

36. Rovai, A. S. et al. Global controls on carbon storage in mangrove soils. Nat. Clim. Change 8, 534-538 (2018).

37. Sanderman, J. et al. A global map of mangrove forest soil carbon at $30 \mathrm{~m}$ spatial resolution. Environ. Res. Lett. 13, 055002 (2018).

38. Bouillon, S. Carbon cycle: storage beneath mangroves. Nat. Geosci. 4, 282-283 (2011).

39. Lovelock, C. E. et al. Assessing the risk of carbon dioxide emissions from blue carbon ecosystems. Front. Ecol. Environ. 15, 257-265 (2017).

40. Fatoyinbo, T., Feliciano, E. A., Lagomasino, D., Lee, S. K. \& Trettin, C. Estimating mangrove aboveground biomass from airborne LiDAR data: a case study from the Zambezi River delta. Environ. Res. Lett. 13, 025012 (2017).

41. Atwood, T. B. et al. Global patterns in mangrove soil carbon stocks and losses. Nat. Clim. Change 7, 523-528 (2017).

42. Chave, J. et al. Tree allometry and improved estimation of carbon stocks and balance in tropical forests. Oecologia 145, 87-99 (2005).

43. Siikamäki, J., Sanchirico, J. N. \& Jardine, S. L. Global economic potential for reducing carbon dioxide emissions from mangrove loss. Proc. Natl Acad. Sci. USA 109, 14369-14374 (2012).

44. Twilley, R. R., Chen, R. H. \& Hargis, T. Carbon sinks in mangroves and their implications to carbon budget of tropical coastal ecosystems. Water Air Soil Pollut. 64, 265-288 (1992).

45. Feka, N. Z. \& Ajonina, G. N. Drivers causing decline of mangrove in West-Central Africa: a review. Int. J. Biodiv. Sci. Ecosys. Serv. Manage. 7 , 217-230 (2011).
46. Omo-Irabor, O. O. et al. Mangrove vulnerability modelling in parts of Western Niger Delta, Nigeria using satellite images, GIS techniques and Spatial Multi-Criteria Analysis (SMCA). Environ. Monit. Assess. 178, 39-51 (2011).

47. Hinson, A. L. et al. The spatial distribution of soil organic carbon in tidal wetland soils of the continental United States. Glob. Chang. Biol. 23, 5468-5480 (2017).

\section{Acknowledgements}

This work was conducted by the Jet Propulsion Laboratory (JPL), California Institute of Technology (Caltech), under contract with the National Aeronautics and Space Administration (NASA). This work was funded by the NASA Land-Cover/Land-Use Change (LCLUC) Program project 'Vulnerability Assessment of Mangrove Forest Regions of the Americas', the NASA Carbon Monitoring System (CMS) project 'Total Carbon Estimation in African Blue Carbon Ecosystems' (14-CMS14-0028), the Florida Coastal Everglades Long-Term Ecological Research program (FCE-LTER; grants nos. DBI-0620409 and DEB-1237517) and the Department of Interior, South-Central Climate Science Center. We furthermore acknowledge funding by the United States Agency for International Development SilvaCarbon Program, the United States Department of Agriculture - Forest Service International Programs and the Center for International Forestry Research (CIFOR) Sustainable Wetlands Adaptation Mitigation (SWAMP) Program for field data collection in Mozambique and Bangladesh. The authors thank M. Rahman (Kyoto University, Japan), Z. Iqbal (SilvaCarbon Bangladesh and Bangladesh Forest Service), I. Ahmed (Bangladesh Forest Service) and the Bangladesh Forest Service for providing access to the Sundarbans Mangrove Carbon Assessment field data. The authors also thank the Agence Nationale des Parcs Nationaux (ANPN) and Centre National de la Recherche Scientifique et Technologique (CENAREST) in Gabon, in particular, K. Jeffery, A. Flore, K. Pambo and L. White for providing field permits and access to Pongara National Park for the validation of canopy heights. The authors thank the Ministerio del Ambiente, Energia y Telecomunicacion (MINAET) for providing the field permits for data collection in Costa Rica, and the Organization of Tropical Studies (Costa Rica), E. Medina (Instituto Venezolano de Investigaciones Cientificas, Venezuela), V.E. Mena Mosquera (Universidad Tecnológica del Chocó, Colombia), M.M. Pozo Cajas (Escuela Superior Politecnica del Litoral, Ecuador), J.E. Pineda Mancera (Universidad Nacional de Colombia, Colombia), M. Obiang (Université Omar Bongo, Gabon) and the Comisión Nacional para el Conocimiento y Uso de la Biodiversidad (CONABIO, Mexico) for in situ field support. Thanks also go to N. Pinto and M. Denbina (JPL, Caltech), R. Aguilar (Vascular Plants of the Osa Peninsula, Costa Rica), A. Armstrong (United Space Research Association/ NASA GSFC, USA), P. Montesano (Sigma Space Applications International/NASA GSFC, USA), G. Sun (University of Maryland and NASA GSFC, USA), A. Vega (AMBICOR, Costa Rica), J. Corcoran (JPL, Caltech, USA), C. Trettin (USDA Forest Service, USA), L. Duncanson (University of Maryland/NASA GSFC), A. Williams (Louisiana State University, USA), H. Tavera (MarViva, Colombia), P. Walfir Souza-Filho, M. Ferreira Cougo and R. Salum (Universidade Federal do Pará, Brazil), I. Longa (Agence Gabonaise d'Etudes et Observations Spaciales, Gabon), S.K. Lee (University of Maryland/GSFC, USA) and D. Lagomasino (University of Maryland/GSFC, USA) for help in the field. The authors thank X.C. Wang (JPL, Caltech) for providing the tidal range data and S.K. Lee, R. Lucas (University of Aberystwith, Wales) and D. Lagomasino for providing edits to the manuscript. Conservation International, through the Blue Carbon initiative, supported identification of knowledge gaps and local stakeholders.

\section{Author contributions}

M.S. and L.F. conceived and designed the study. M.S. led the SRTM and ICESat/ GLAS data processing, with assistance from C.S., L.F. and N.T. Field data processing and biomass model development were led by L.F., with assistance from M.S. Field experimental design and data collection were carried out by M.S., L.F., V.R.-M., E.C.-M. and N.T. The interpretation of data and generation of results were performed by M.S., L.F., C.S., V.R.-M., E.C-M., T.V.D.S. and N.T. The writing of the paper was led by M.S. and L.F., with input from all co-authors.

\section{Competing interests}

The authors declare no competing interests.

\section{Additional information}

Supplementary information is available for this paper at https://doi.org/10.1038/ s41561-018-0279-1.

Reprints and permissions information is available at www.nature.com/reprints. Correspondence and requests for materials should be addressed to M.S. or L.F.

Publisher's note: Springer Nature remains neutral with regard to jurisdictional claims in published maps and institutional affiliations.

(c) The Author(s), under exclusive licence to Springer Nature Limited 2018 


\section{Methods}

Mangrove canopy height estimation with SRTM and ICESat/GLAS. The global maps of canopy height were generated using SRTM DEM data ${ }^{48}$ collected in February 2000 and lidar heights from the ICESat/GLAS Spaceborne Lidar mission following a methodology that was successfully implemented on regional scales in Florida, Colombia and across Africa, with root-mean-square error (r.m.s.e.) values of $3 \mathrm{~m}$ or lower across the $1-30 \mathrm{~m}$ mean height range ${ }^{23,49-51}$. The SRTM DEM values report elevations located at the InSAR scattering phase height centre, which corresponds to a height located between the ground elevation and the top of the canopy ${ }^{23,49,52}$ in vegetated areas. This is due to radar microwaves penetrating and interacting within the forest canopy, rather than with the top of the canopy or ground alone. To identify mangrove areas and mask non-mangrove regions in the SRTM elevation data set, we used the global mangrove extent map from ref. ${ }^{26}$. We only included areas with SRTM elevation values ranging from 0 to $55 \mathrm{~m}$ above mean sea level to remove some areas falsely identified as mangroves in the ref. ${ }^{26}$ map. This threshold value preserves the tallest mangrove forest stands (Fig. 3). This map was preferred over the more recent map developed by Hamilton and Casey ${ }^{12}$ as it is coincidental with the SRTM data set (that is, they are both from 2000) and, so far, it is the only one that specifically maps mangroves from Landsat data, as opposed to using global canopy cover from the Global Forest Change product ${ }^{53}$.

GLAS lidar altimetry data were collected globally from 2003 to 2009, providing the only global lidar canopy and height measurement, with sparse samples distributed across the globe. We used GLAS data to remove the elevation bias introduced by the limited penetration of the SRTM C-band microwave signal within the forest canopy, which allows for spatially comprehensive and accurate mapping of canopy height ${ }^{51}$. The GLAS lidar-derived maximum canopy height is defined as the height of the lidar pulse containing all its energy between the ground and the top of the tallest tree (referred to as the relative height of the 100th percentile, RH100). We found a total of 57,369 lidar waveforms in mangrove areas using the entire GLAS archive spanning 2003-2009, filtering out the low-quality measurements $\mathrm{s}^{27}$ and intersecting the GLAS estimates of maximum canopy height with the SRTM mangrove extent subset. Supplementary Fig. 5 presents a scatterplot of RH100 and SRTM elevation in mangrove areas. We applied regression model (1) relating GLAS RH100 to SRTM elevation measurements (Supplementary Fig. 5) to obtain a global map of maximum canopy height:

$$
\mathrm{SRTMH}_{\text {max }}=1.697 \times H_{\text {SRTM }}
$$

where $H_{\text {SRTM }}$ represents the original SRTM DEM, and SRTMH $H_{\max }$ is the new maximum canopy height data set. Regions with an SRTM elevation of $0 \mathrm{~m}$ but mapped as mangroves in the ref. ${ }^{26}$ map were assigned a default value of $0.5 \mathrm{~m}$ (based on field observations) as these are most probably scrub or low-density mangrove forests that could not be detected by SRTM. We computed the mean and maximum $\mathrm{SRTMH}_{\max }$ values for each country, as shown in Supplementary Tables 2-6. In total, we report all of the results obtained for 117 countries and territories. We defined the maximum $\mathrm{SRTMH}_{\max }$ as the 95th percentile value in each country to minimize the impact of canopy height error reported from a potentially small number of misclassified pixels. For countries with the tallest forests $(>40 \mathrm{~m})$, we identified the exact location of these forest stands to visually ascertain that each region included more than one pixel representing tall mangroves, and especially to avoid confusing the maximum SRTMH max $_{\text {max }}$ with local topographic features included within the mangrove mask ${ }^{26}$. In countries and territories with small mangrove areas close to steep topography, higher topographic areas inland from mangrove fringe were often falsely classified as mangroves. In these cases, mostly occurring over islands such as Japan, Palau, Samoa, the Solomon Islands and Fiji, the use of the 95th percentile to determine $\mathrm{SRTMH}_{\max }$ did not suffice to remove outliers, and we therefore do not report their maximum SRTMH $\mathrm{m}_{\max }$ value (Supplementary Tables 2-6). Finally, the SRTM estimates of $H_{\max }$ (that is, $\mathrm{SRTMH}_{\max }$ ) were validated with in situ measurements of $H_{\max }$ with an $R^{2}$ of 0.73 and an r.m.s.e. of $6.31 \mathrm{~m}$ globally (Supplementary Fig. 1b). In February of 2016, in situ measurements of $H_{\max }$ were collected in Pongara National Park (Fig. 3) to confirm the validity of the tallest canopy height values in Gabon. Here, the heights of five of the tallest observed trees were measured using a laser rangefinder, confirming the location of the areas with the tallest mangrove canopy in the world (with all five trees measuring between $62 \mathrm{~m}$ and $65 \mathrm{~m}$; Fig. 3 ).

In addition to $H_{\max }$, we also generated a map of $H_{\mathrm{ba}}$, the basal area weighted height, which was used as input for the AGB map. We chose $H_{\text {ba }}$ because it has a lower r.m.s.e. for the height estimate (Supplementary Fig. 1) and there were more field data available for biomass model generation (we did not have $H_{\max }$ values for the Bangladesh data). The smaller r.m.s.e. is also expected as $H_{\mathrm{ba}}$, like biomass, is a function of basal area. We calculated $\mathrm{SRTMH}_{\mathrm{ba}}$ by relating field values of $H_{\mathrm{ba}}$ (described in the section below) to SRTM DEM elevations (Supplementary Fig. 1):

$$
\mathrm{SRTMH}_{\mathrm{ba}}=1.0754 \times H_{\mathrm{SRTM}}
$$

where $H_{\text {SRTM }}$ represents the original SRTM DEM and $\mathrm{SRTMH}_{\mathrm{ba}}$ the new basal area weighted canopy height data set.
Height uncertainty. The combination of multiple data sets and the global approach of our study inevitably introduces some degree of uncertainty into our results. In the case of mangrove height, the $\mathrm{SRTMH}_{\mathrm{ba}}$ data had an r.m.s.e. of $3.6 \mathrm{~m}$ when compared to in situ $H_{\text {ba }}$ measurements (shown in Supplementary Fig. 1). This means that in any particular pixel, if our $\mathrm{SRTMH}_{\mathrm{ba}}$ map indicates a $4 \mathrm{~m}$ mangrove forest, the in situ $H_{\mathrm{ba}}$ is likely to be between $0.4 \mathrm{~m}$ and $7.6 \mathrm{~m}$. However, the $\mathrm{SRTMH}_{\max }$ uncertainty is larger, as indicated by the regression with GLAS RH100 (r.m.s.e. of $5.7 \mathrm{~m}$ ) (Supplementary Fig. 5) and in situ $H_{\max }$ (r.m.s.e. of $6.31 \mathrm{~m}$ ). Nonetheless, both height estimates are more accurate than the elevation errors reported for the global SRTM $\mathrm{DEM}^{54}$ as we are only studying relative height in flat coastal areas where the impacts of topography on the DEM error are reduced. While our estimated height uncertainty is significant at the $30 \mathrm{~m}$ pixel scale, it is random, and therefore our global data products allow for the analysis of canopy structure trends at regional and continental scales.

The regression residuals between the SRTM height estimates, the GLAS RH100 or field results originate from several sources of uncertainty, discrepancies in the spatial scale, and the timing of measurements. There are inherent system errors associated with the GLAS and SRTM sensors, field measurement errors, geo-location errors and discrepancies in spatial resolution ${ }^{51}$ between the $30 \mathrm{~m}$ SRTM pixel, the $70 \mathrm{~m}$ GLAS footprint and the various plot sizes used in this study. Additionally, these measurements were acquired over different periods (February 2000 for SRTM; 2003-2009 for GLAS; 2004-2016 for field measurements) and are therefore impacted by natural changes in the canopy structure over time. A detailed analysis of differences in canopy height obtained from SRTM, lidar and field measurements ${ }^{52}$ showed that SRTM height is sufficiently constant over time to measure canopy height in established mangrove forests.

In situ forest height and biomass estimation. Our selected field sites (331 plots in total) included a wide variety of forest structure and mangrove ecotypes (for example, scrub, fringe, riverine and basin) with measured in situ tree heights ranging from 1 to $65 \mathrm{~m}$ (Supplementary Table 1). The mangrove field sites were distributed along a latitudinal range from $26^{\circ} \mathrm{S}$ (Maputo Reserve, Mozambique) to $25^{\circ} \mathrm{N}$ (Everglades, USA), encompassing the equatorial region (for example, Chocó, Colombia). Field data were used to estimate forest structure attributes (that is, $H_{\mathrm{ba}}, H_{\max }$ and AGB). Most of the data were collected in field plots throughout the Americas and Africa, using fixed or variable plot sizes ${ }^{49}$ (Supplementary Fig. 4 and Supplementary Table 1). Within variable plots, trees were selected using a fixed-angle gauge. For each selected tree, we identified the species and measured the diameter at breast height (DBH) and height using a laser rangefinder or clinometer. Tree density (that is, the no. of stems) was estimated for each plot and expressed per unit area (in ha). Generally, the plot size depended on the largest tree size at each forest site. For instance, in Chocó (Colombia), where trees were very tall and tree density was low, we used a $25 \mathrm{~m}$ fixed-radius plot, while on Inhaca Island (Mozambique), where trees were small and tree density was high, plots had a $7.5 \mathrm{~m}$ radius. In the Zambezi River Delta (Mozambique), 40 plots of 0.52 ha were sampled with subplots ${ }^{55,56}$ each with a radius between $3 \mathrm{~m}$ and $5 \mathrm{~m}$. On Inhaca Island (Mozambique), we sampled 51 plots with a radius of $7.5 \mathrm{~m}(0.0176 \mathrm{ha})^{50}$. For all sites, we computed field basal area weighted height $H_{\mathrm{ba}}$ as

$$
H_{\mathrm{ba}}=\frac{\sum_{i}\left(\pi r_{i}^{2} \times H_{i}\right)}{\sum_{i}\left(\pi r_{i}^{2}\right)}
$$

where $H_{\mathrm{i}}$ and $r_{\mathrm{i}}$ are the height and radius (that is, $\mathrm{DBH} / 2$ ) of tree $i$, respectively, in metres. $H_{\text {ba }}$ accounts for tree size, which means larger trees have a stronger impact on the forest height estimate. $H_{\max }$ was defined as the height of the tallest tree within a plot. In situ data were collected within the 15 -year period after the SRTM data were obtained.

Global trends in mangrove structure. To test whether spatial trends in mangrove canopy structure are associated with temperature, precipitation and tidal range, we used the WorldClim ${ }^{57}$ model, and tidal outputs from the ocean model developed by Wang and colleagues ${ }^{58}$. The analysis of canopy height trends with these climate and environmental variables (WorldClim annual mean temperature, mean temperature of warmest quarter, standard deviation of monthly mean temperature, mean of coldest quarter, annual precipitation and SSS) was performed by intersecting a circle with a radius of $10 \mathrm{~km}$ centred on the coastline with mangroves every half degree in latitude and intersecting the coastline at least $20 \mathrm{~km}$ apart in the longitudinal direction. Cyclone frequency and distribution from 1842 to 2016 were calculated from the NOAA International Best Track Archive for Climate Stewardship (IBTrACS version 3 release 9). In this data set the tropical cyclone occurrences are shown as points along their path. To generate a histogram of cyclone frequency and distribution, we computed the percentage of these points overlapping with mangrove areas, adding a buffer zone of $1.5^{\circ}$ to the mangrove location. The buffer zone was added to include all tropical cyclones potentially influencing mangrove growth. Previous studies show that precipitation and temperature are climatic variables that regulate mangrove ecosystem structure (for example, height and biomass) and function (that is, productivity) ${ }^{17,18}$. Tidal range was computed as the minimum and maximum sea surface height considering annual variations of four semidiurnal constituents and four diurnal constituents. 
The mean SSS as a function of latitude for each continental region (Fig. 4b) was generated using 44 monthly mean maps (from 2011 and 2015) from version 4 of the Aquarius CAP Level 3 product $^{59}$. The sampled environmental variables were averaged per $1^{\circ}$ of latitude, ranging from $34^{\circ} \mathrm{S}$ to $30^{\circ} \mathrm{N}$. The occurrence of cyclones was counted per $1^{\circ}$ interval. A multivariate regression analysis demonstrated the significant relationships between some environmental variables and mangrove structure (that is, maximum height) (Supplementary Table 7). Initially, all aforementioned variables were included in the analysis with insignificant (that is, $P>0.05$ ) and highly correlated variables (for example, minimum temperature and mean temperature) gradually eliminated. Only temperature, precipitation and cyclone landfall frequency remained, explaining $74 \%$ of observed global trends in mangrove maximum canopy height (Supplementary Table 7). Further analysis also showed that precipitation alone explained $57 \%$ of global canopy height trends while temperature alone explained 53\%. Together, precipitation and temperature explained $71 \%$ of global canopy height trends. The multivariate regression and variance inflation factor calculation were performed using the python statsmodel module ${ }^{60}$. All of the remote sensing data processing and analysis were carried out using the Python scripting language, Quantum Geographical Information System $(\mathrm{QGIS})^{61}$, the Geospatial Abstraction Library (GDAL), the Remote Sensing and GIS python library (RSGISLib) ${ }^{62}$ and GNU Parallel ${ }^{63}$.

Global mangrove biomass allometry development. We used the in situ field data sets to derive stand-level allometry between AGB, basal area weighted height $H_{\mathrm{ba}}$ and maximum canopy height $H_{\max }$. AGB was estimated for each individual tree tagged inside the plot, using regional or site-specific allometric equations as described by previous studies ${ }^{23,40,50,64}$. We used the generalized pantropical tree allometric mode ${ }^{65}$ with species-specific wood density from the global wood density database ${ }^{66}$ to calculate the above- and belowground (root) biomass of individual trees (Supplementary Table 1). The sum of individual trees within the plot was then computed and normalized, using plot sizes, to represent total forest stand AGB density in $\mathrm{Mgha}^{-1}$. We then generated regional and global models between plot-level canopy height and plot-level AGB density, where height and AGB relationships were fitted to the regression model:

$$
\mathrm{AGB}=a \times H_{x}^{\mathrm{b}}
$$

where $H_{x}$ can represent either $H_{\mathrm{ba}}$ or $H_{\max }$. The allometric parameters $a$ and $b$ are fitted. The global model was generated using all of the plot data $(n=331)$ and $H_{\text {ba }}$ of the field data, while the regional models were generated for the Americas (using data from Colombia, USA, Venezuela, Brazil, Costa Rica, Ecuador, Mexico, $n=81$ ), East Africa (using data from Mozambique, $n=101$ ) and South Asia (using data from Bangladesh, $n=149$ )

The analysis of the field data and the allometric regression models between field height and AGB confirmed that while canopy height alone explains most of the variability in AGB, adding stem density or basal area to the model, as in the case of $H_{\mathrm{b}}$, and developing region-specific regressions, improved the relationship (Supplementary Fig. 4). In addition, $H_{\mathrm{ba}}$ is computed from multiple tree measurements, which reduces systematic and random height measurement error at the stand level, as opposed to $H_{\mathrm{max}}$, which is reported from a single tree measurement. Supplementary Fig. 4 shows the relationship of AGB with $H_{\mathrm{ba}}$ on a global scale as well as region-specific scales.

Three region-specific allometric models were derived from field data for East Africa, the Americas and Middle East Asia. For Southeast Asia and Australia, a published allometric model was used ${ }^{64}$. Finally, for West Africa, we applied the global allometric equation, as no field data were available to generate a regional allometry. The regional biomass allometric models developed in this study have r.m.s.e. values ranging from $54.3 \mathrm{Mgha}^{-1}$ to $103.4 \mathrm{Mg} \mathrm{ha}^{-1}$. All models generated for this study are shown in Supplementary Fig. 4, and all models used in the study can be found in Supplementary Table 8.

Large-scale AGB estimation with SRTM. The global mangrove forest AGB map was generated by linking the field-measured biomass-height allometry (described above) with SRTM estimates of $H_{\mathrm{ba}}$ (that is, $\mathrm{SRTMH}_{\mathrm{ba}}$ ). This procedure implies a two-step process where SRTM is converted to $\mathrm{SRTMH}_{\mathrm{ba}}$ and then to AGB using appropriate field-derived $H_{\mathrm{ba}}$ to AGB allometry (Supplementary Table 8). This approach is meant to facilitate potential updates by the user community as more regional height-to-biomass models are developed. Supplementary Fig. 1a shows the relationship between SRTM elevation and field-measured canopy height data, used to convert SRTM elevation to SRTMH $\mathrm{Ha}_{\mathrm{ba}}$. Using this method, the predicted AGB was estimated with an accuracy of $84.2 \mathrm{Mgha}^{-1}$ at the plot level (Supplementary Fig. 6)

Finally, total (above- and belowground) biomass and carbon stock estimates by country were generated by summing all corresponding pixels, while accounting for belowground biomass and soil carbon. We computed the total aboveground carbon stocks per country, assuming a stoichiometric factor of 0.451 as the AGB conversion factor, following the IPCC guidelines ${ }^{67}$. We also accounted for belowground carbon and root biomass using published allometric models ${ }^{42,68}$. It is important to note that all allometric equations are site-specific and extrapolation may result in a bias. For instance, in the Florida Everglades, root biomass in scrub forests can be three to four times higher compared to $\mathrm{AGB}^{69}$. Furthermore, most allometric models do not account for scrub forests, thereby adding uncertainty to the AGB and total carbon estimates. Nevertheless, we believe we have used the most complete data sets and the most accurate values currently available, which can be updated as new global belowground data and new allometry become available. Country-wide belowground carbon stocks were estimated with a mean of $283 \mathrm{MgCha}^{-1}$ within the top $1 \mathrm{~m}$ of soils ${ }^{41}$. Total root biomass was estimated as $49 \%$ of the AGB following the IPCC guidelines ${ }^{67}$. These generic values, uncertainties in the allometric models, as well as the uncertainty of $12 \%^{26}$ in the mangrove extent map, will propagate as a bias in country-wide totals.

\section{Data availability}

The data that support the findings of this study are available from the Oak Ridge National Data Archive (ORNL DAAC; https://doi.org/10.3334/ORNLDAAC/1665) as GEOTIFF files and as an online webmapping tool (https://mangrovescience. earthengine.app/view/mangroveheightandbiomass). The in situ field data that have not been published previously are also available through the ORNL DAAC as .csv files listing individual tree measurements (https://doi.org/10.3334/ ORNLDAAC/1665). The SRTM and ICESat/GLAS data sets used as input to generate the maps can be downloaded from https://lta.cr.usgs.gov/SRTM and https://nsidc.org/data/icesat/data.html, respectively. The global mangrove map ${ }^{26}$ is freely available at http://data.unep-wcmc.org/datasets/4. The tropical cyclone and SSS data are available from NOAA archives https://data.nodc.noaa.gov/cgi-bin/ iso?id=gov.noaa.ncdc:C00834 (https://doi.org/10.7289/V5NK3BZP) and https:// podaac.jpl.nasa.gov/dataset/AQUARIUS_L3_SSS_CAP_MONTHLY_V4?ids= Platform\&values=AQUARIUS_SAC-D (https://doi.org/10.5067/AQR40-3TMCS). The WorldClim data are available at http://worldclim.org/version2.

\section{References}

48. Farr, T. et al. The Shuttle Radar Topography Mission. Rev. Geophys. 45, RG2004 (2007).

49. Simard, M. et al. Mapping height and biomass of mangrove forests in Everglades National Park with SRTM elevation data. Photogramm. Eng. Remote Sens. 72, 299-311 (2006)

50. Fatoyinbo, T. E., Simard, M., Washington-Allen, R. A. \& Shugart, H. H. Landscape-scale extent, height, biomass, and carbon estimation of Mozambique's mangrove, forests with Landsat ETM+ and Shuttle Radar Topography Mission elevation data. J. Geophys. Res. Biogeosci. 113, G02S06 (2008).

51. Fatoyinbo, T. E. \& Simard, M. Height and biomass of mangroves in Africa from ICESat/GLAS and SRTM. Int. J. Remote Sens. 34, 668-681 (2013).

52. Lagomasino, D., Fatoyinbo, T., Lee, S. \& Feliciano, E. A. Comparison of mangrove canopy height using multiple independent measurements from land, air, and space. Remote Sens. 8, 327 (2016).

53. Hansen, M. C. et al. High-resolution global maps of 21st-century forest cover change. Science 342, 850-853 (2013).

54. Rodríguez, E., Morris, C. S. \& Belz, E. A global assessment of the SRTM performance. Photogramm. Eng. Remote Sens. 72, 249-260 (2006).

55. Stringer, C. E. et al. The Zambezi River Delta Mangrove Carbon Project: A Pilot Baseline Assessment for REDD+ Reporting and Monitoring. Final Report 1-56 (United States Forest Service, 2014).

56. Trettin, C. C., Stringer, C. E. \& Zarnoch, S. J. Composition, biomass and structure of mangroves within the Zambezi River Delta. Wetl. Ecol. Manag. 24, 173-186 (2015).

57. Fick, S. E. \& Hijmans, R. J. WorldClim 2: new 1-km spatial resolution climate surfaces for global land areas. Int. J. Climatol. 37, 4302-4315 (2017).

58. Wang, X., Chao, Y., Shum, C. K., Yi, Y. \& Fok, H. S. Comparison of two methods to assess ocean tide models. J. Atmos. Ocean. Technol. 29, 1159-1167 (2012)

59. Yueh, S. H., Tang, W., Hayashi, A. K. \& Lagerloef, G. S. E. L-band passive and active microwave geophysical model functions of ocean surface winds and applications to Aquarius retrieval. IEEE Trans. Geosci. Remote Sens. 51, 4619-4632 (2014)

60. Seabold, S. \& Perktold, J. Statsmodels: econometric and statistical modeling with Python. Proc. 9th Python Sci. Conf. 57-61 (2010).

61. QGIS Development Team. QGIS Geographic Information System. Open Source Geospatial Foundation Project (2018); https://www.osgeo.org/projects/qgis/

62. Bunting, P., Clewley, D., Lucas, R. M. \& Gillingham, S. The Remote Sensing and GIS Software Library (RSGISLib). Comput. Geosci. 62, 216-226 (2014)

63. Tange, O. GNU Parallel 2018 (2018); https://doi.org/10.5281/zenodo.1146014

64. Aslan, A., Rahman, A. F., Warren, M. W. \& Robeson, S. M. Mapping spatial distribution and biomass of coastal wetland vegetation in Indonesian Papua by combining active and passive remotely sensed data. Remote Sens. Environ. 183, 65-81 (2016)

65. Chave, J. et al. Improved allometric models to estimate the aboveground biomass of tropical trees. Glob. Chang. Biol. 20, 3177-3190 (2014). 
66. Chave, J. et al. Towards a worldwide wood economics spectrum. Ecol. Lett. 12, 351-366 (2009).

67. Hiraishi, T. et al. 2013 Supplement to the 2006 IPCC Guidelines for National Greenhouse Gas Inventories: Wetlands. Methodological Guidance on Lands with Wet and Drained Soils, and Constructed Wetlands for Wastewater Treatment (IPCC, 2014).
68. Komiyama, A., Ong, J. E. \& Poungparn, S. Allometry, biomass, and productivity of mangrove forests: a review. Aquat. Bot. 89, 128-137 (2008).

69. Castañeda-Moya, E. et al. Patterns of root dynamics in mangrove forests along environmental gradients in the Florida coastal Everglades, USA. Ecosystems 14, 1178-1195 (2011). 